\title{
TABLE S21
}

\begin{tabular}{|c|c|c|c|c|}
\hline PROMISCUOUS PROTEIN & DIP ID NUMBER & ORGANISM & EVALUE & DIP PROTEIN DESCRIPTION \\
\hline 1 FYN SH3 & DIP:198N & Mus musculus & 2.00E-29 & Protein-tyrosine Kinase Fyn \\
\hline 2 IMPORTIN BETA & DIP:2357N & Saccharomyces cerevisiae & $3.00 \mathrm{E}-82$ & KAP95 Protein \\
\hline 3 OVOMUCOID INHIBITOR & N/A & N/A & N/A & N/A \\
\hline 4 CHEY & DIP:6052N & Escherichia coli & 8.00E-38 & Chemotaxis Protein CheY \\
\hline 5 THIOREDOXIN & DIP:5552N & Saccharomyces cerevisiae & $4.00 \mathrm{E}-12$ & Thioredoxin I \\
\hline 6 HPR & DIP:6180N & Escherichia coli & 1.00E-09 & Phosphocarrier protein $\mathrm{HPr}$ (Histidine-containing protein) \\
\hline 7 IL6 & DIP:95N & Homo sapiens & $1.00 \mathrm{E}-179$ & Membrane Glycoprotein GP130 Precursor \\
\hline 8 BETA LACTAMASE & N/A & N/A & N/A & $\mathrm{N} / \mathrm{A}$ \\
\hline 9 ELASTASE & DIP:378N & Sus scrofa domestica & $1.00 \mathrm{E}-132$ & Pancreatic Elastase I Precursor \\
\hline 10 PPR & DIP:241N & Homo sapiens & $6.00 \mathrm{E}-97$ & Peroxisome Proliferator-activated Receptor \\
\hline 11 RAN & DIP:1357N & Saccharomyces cerevisiae & $1.00 \mathrm{E}-101$ & GTP-binding protein GSP2 \\
\hline 12 RAS & DIP:2263N & Saccharomyces cerevisiae & $3.00 \mathrm{E}-47$ & GTP-binding protein RAS2 \\
\hline 13 ACTIN & DIP:310N & Saccharomyces cerevisiae & 0 & actin \\
\hline 14 TRANSDUCIN BETA GAM & DIP:954N & Saccharomyces cerevisiae & 2.00E-66 & GTP-binding protein beta chain STE4 \\
\hline 15 FC IGG1 & N/A & N/A & N/A & $N / A$ \\
\hline 16 RAC & DIP:862N & Drosophila melanogaster & $1.00 \mathrm{E}-96$ & GTP-binding Protein Rac2 \\
\hline 17 UBIQUITIN & DIP:1549N & Saccharomyces cerevisiae & $9.00 \mathrm{E}-32$ & Ubiquitin \\
\hline 18 CDC42 & DIP:862N & Saccharomyces cerevisiae & $4.00 \mathrm{E}-87$ & Cell Division Control Protein CDC42 \\
\hline 19 RXR RECEPTOR & DIP:641N & Homo sapiens & $1.00 \mathrm{E}-138$ & Retinoic Acid Receptor X-alpha \\
\hline 20 PAPD & DIP:6196N & Escherichia coli & $1.00 \mathrm{E}-120$ & Chaperone Protein PapD Precursor \\
\hline
\end{tabular}

